\title{
Double outlet right ventricle with 1-malposition of the aorta
}

\author{
Christopher Lincoln, Robert H. Anderson, ${ }^{1}$ Elliot A. Shinebourne, Terence A. H. English, and \\ James L. Wilkinson \\ From the Department of Paediatric Cardiology, Brompton Hospital; Cardiothoracic Institute, University of \\ London; Addenbrooke's Hospital, Cambridge; and Department of Child Health, University of Liverpool
}

Four patients are described with a recently recognized variant of double outlet right ventricle.

Clinical examination favoured tetralogy of Fallot, but the chest $\mathrm{x}$-ray suggested corrected transposition. Catheterization and angiocardiography showed that the aorta was to the left of the main pulmonary artery, and both arose from a normally positioned morphological right ventricle. Egress of blood from the left ventricle was through a subaortic ventricular septal defect. In all patients severe pulmonary stenosis was present and the right coronary artery ran an anomalous course anterior to the pulmonary valve ring.

Two children had successful total correction, and one a palliative Blalock-Taussig shunt. Necropsy material from the fourth patient allowed confirmation of the ventricular morphology and the conducting tissue was examined. In corrective surgery, blood from the left ventricle was rerouted into the aorta by an intraventricular baffle. Pulmonary stenosis was relieved by infundibulectomy and an outflow tract patch.

Paul, Van Praagh, and Van Praagh (1968) described a variant of double outlet right ventricle in which the aorta arose to the left of the pulmonary artery despite a d-bulboventricular loop. This condition, subsequently termed double outlet right ventricle with l-malposition by Van Praagh (1973a) is particularly amenable to surgical correction because of the subaortic position of the ventricular septal defect (Lincoln, 1972; Danielson et al., 1972). We have subsequently studied 3 cases in addition to the patient corrected by Lincoln (1972). Two of these 4 patients have been corrected and a third palliated, while histopathological examination has been conducted on a fourth necropsy specimen.

In view of the good surgical prognosis, we consider it appropriate to document the clinical, angiocardiographic, and surgical features of the anomaly, and to consider its possible embryogenesis.

Case I

\section{Case reports}

A 7-year-old girl had previously been investigated at another hospital, where a Fallot-like situation had been diagnosed. Surgical exploration to correct this anomaly was abandoned when the great arteries were found to be abnormally arranged.

Received 30 July 1974.

${ }^{1}$ R.H.A. is a British Heart Foundation Senior Research Fellow.
Physical examination The child was cyanosed and her fingers clubbed. The jugular venous pressure was normal, and a right parasternal heave was palpable. The first heart sound was normal, the second single, and a soft ejection systolic murmur was present maximal at the third left intercostal space. Haemoglobin was $19.6 \mathrm{~g} / \mathrm{dl}$ and PCV 60 per cent.

Electrocardiogram showed sinus rhythm, right atrial and right ventricular hypertrophy. $P$ wave axis was $+60^{\circ}$ and the mean frontal plane QRS axis was $+120^{\circ}$. A small ( $I \mathrm{~mm}$ ) $Q$ wave was seen in $V_{4} R$ but no $Q$ waves were seen in $\mathrm{V} 6$ or $\mathrm{V}_{7}$.

The chest $x$-ray showed a normal heart size with a prominent right heart border and diminished pulmonary vascular markings. The left upper border of the cardiac silhouette was straight and no discrete pulmonary segment was seen (Fig. ra).

Special investigations Cardiac catheterization data are shown in the Table. Angiocardiography showed that the aorta and the pulmonary artery filled from an anterior right-sided morphological right ventricle, and there was some degree of subpulmonary stenosis. The morphological left ventricle was posterior and to the left and ejected contrast medium through a ventricular septal defect to fill the pulmonary artery and aorta synchronously (Fig. 2). Aortography showed a left-sided anterior ascending aorta with a right coronary artery which passed anteriorly to the pulmonary valve ring. The ductus was closed but large bronchial vessels were visible. 

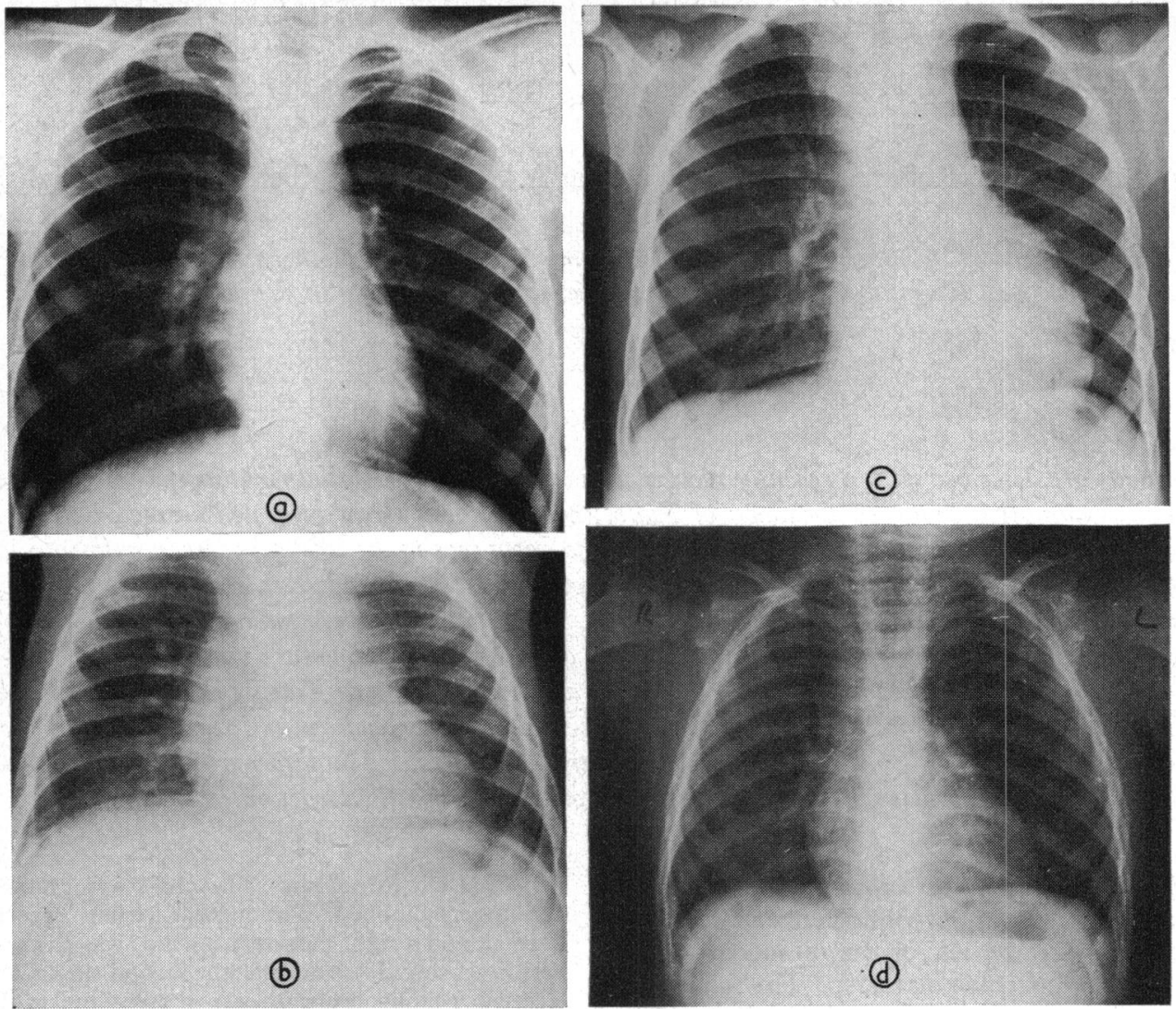

FIG. I a-d) PA chest $\mathrm{x}$-rays of the 4 patients. The pulmonary artery knuckle is absent and the left upper cardiac silhouette is straight in all of them.

Treatment The diagnosis was made at operation, on II May 1971, through a median sternotomy (C.L.). Large bronchial vessels were visible. A systolic thrill was palpable over the main pulmonary artery, which was onethird the diameter of the aorta. The aorta was to the left and in the same frontal plane as the pulmonary artery. For cardiopulmonary bypass, cannulae were inserted into the ascending aorta and the superior and inferior venae cavae. The patient was then cooled to $15^{\circ} \mathrm{C}$ and circulation stopped. The right ventricle was opened through an oblique ventriculotomy avoiding major coronary artery branches. A subaortic ventricular septal defect measuring $2 \mathrm{~cm} \times 1.5 \mathrm{~cm}$ was noted and the subpulmonary area was partially obstructed by hypertrophied muscle and fibrous tissue. Both semilunar valves were tricuspid and the pulmonary valve ring was onethird the size of the aortic valve ring. A thin I to $2 \mathrm{~mm}$ fibrous ridge was present above the cavity of the right ventricle separating the two valve rings (conus septum). A further muscular band separated the semilunar from the atrioventricular valve rings, and the left margin of this band formed the rim of the ventricular septal defect (Fig. 3A).

The hypertrophied parietal trabeculae were excised, enabling the free wall of the right ventricle to be mobilized. This in turn made it possible to admit a I cm bougie into the pulmonary artery. A patch of knitted 'teflon' was then fixed into place with interrupted 4/o sutures, buttressed with small pieces of 'dacron' felt. In this way, the blood was rerouted from the left ventricle to the aorta, and the ventricular septal defect was closed. In the area of fusion of the valve rings, it was possible to place sutures into the fibrous ridge between the semilunar valve rings (conus septum) (Fig. 3B). The right ventriculotomy was repaired following closure of a large patent foramen ovale. The main pulmonary artery was incised in its vertical axis down and across the pulmonary valve ring. The right coronary artery which had been shown preoperatively to cross the pulmonary valve ring was dissected out and retracted from this position. An inlay patch of 'dacron' was then sutured into place, thus widening the pulmonary artery and valve rings (Fig. ${ }_{3} \mathrm{C}$ ). 


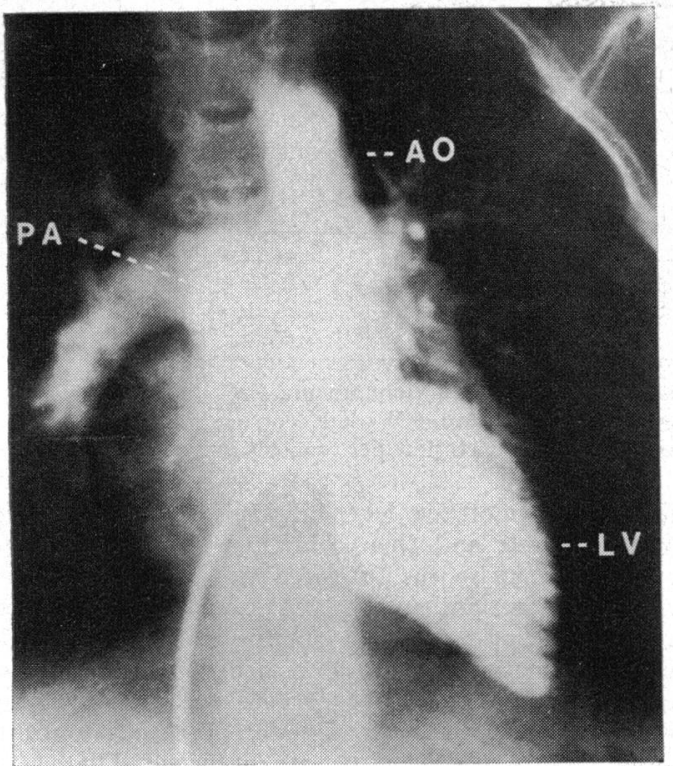

$A$

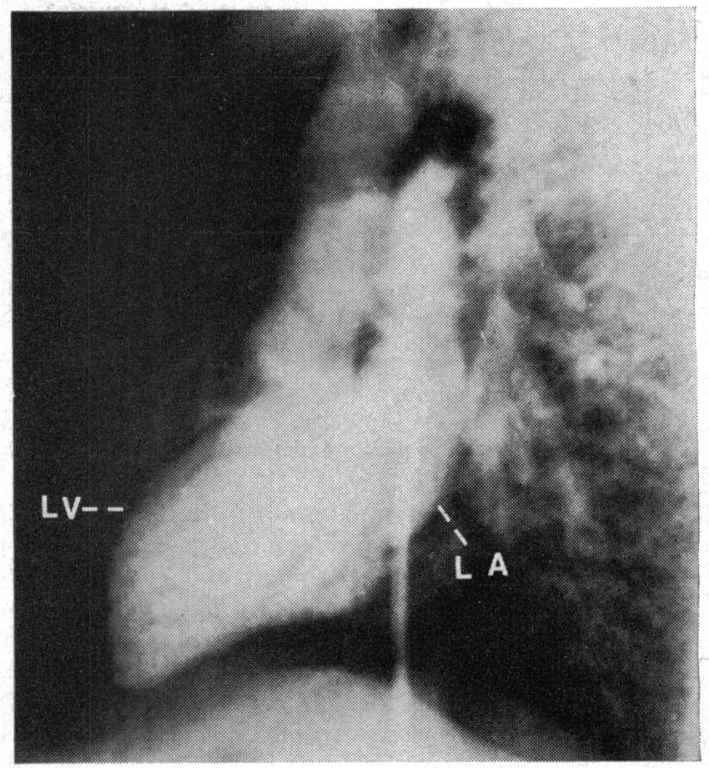

$B$

FIG. 2 Case $I$. Anteroposterior $(A)$ and lateral $(B)$ angiocardiogram. Injection into the left atrium $(L A)$ showing sequential filling of a morphological left ventricle $(L V)$, and the aorta $(A O)$ and pulmonary artery $(P A)$ synchronously via a ventricular septal defect. The pulmonary artery is to the right of the aorta and on the same plane.

(For full operative details see previous report - Lincoln, 1972.)

\section{Case 2}

This patient was referred with severe cyanosis soon after birth. Immediate cardiac catheterization was performed, transposition of the great arteries diagnosed, and balloon septostomy carried out. The baby was initially improved by this procedure but at $\mathrm{I} \frac{1}{2}$ years of age he was more cyanosed, particularly on crying.

Physical examination At this stage, the child was well nourished, but cyanosed at rest. The jugular venous pressure and peripheral pulses were normal. The first heart sound was normal, the second single, and a grade $3 / 6$ ejection systolic murmur was heard maximally in the third left intercostal space. Haemoglobin $17.4 \mathrm{~g} / \mathrm{dl}$, PCV 59 per cent. Electrocardiogram showed sinus rhythm and evidence of right atrial and right ventricular hypertrophy. The $P$ wave axis was $+70^{\circ}$ and the mean frontal plane $Q R S$ axis $+150^{\circ}$. $Q$ waves were prominent over the left but not over the right praecordial leads. Chest $x$-ray showed situs solitus and diminished pulmonary vascular markings. The heart was enlarged and there was a prominent thymic shadow. A left-sided ascending aorta was seen, but the pulmonary segment was absent (Fig. Ib).

Special investigations Cardiac catheterization data are tabulated in the Table. Angiocardiography showed double outlet right ventricle, 1-malposition, pulmonary stenosis, and an absent left pulmonary artery (Fig. 4).

Treatment A palliative systemic right pulmonary artery anastomosis was constructed (Blalock-Taussig). This procedure decreased the child's cyanosis and he is awaiting final corrective surgery.

\section{Case 3}

A 5-year-old girl, in whom cyanosis was first noticed at Io days of age: in the last 2 years exercise tolerance had diminished and cyanosis had increased. There was no history of squatting.

Physical examination The child was cyanosed, clubbed, and below the third percentile for height and weight. There was a prominent parasternal impulse. The first heart sound was normal and the second single. There was a soft systolic murmur maximal at the second left intercostal space.

Electrocardiogram showed sinus rhythm, and right atrial and ventricular hypertrophy. $Q$ waves were present over the left, but not right praecordial leads. QRS axis $+180^{\circ}$.

Special investigations The haemodynamic findings at cardiac catheterization are shown in the Table. Angiocardiography revealed double outlet right ventricle with 1-malposition. Pulmonary stenosis was present at valvar and at infundibular levels. 
TABLE Cardiac catheterization data: Cases I to 3

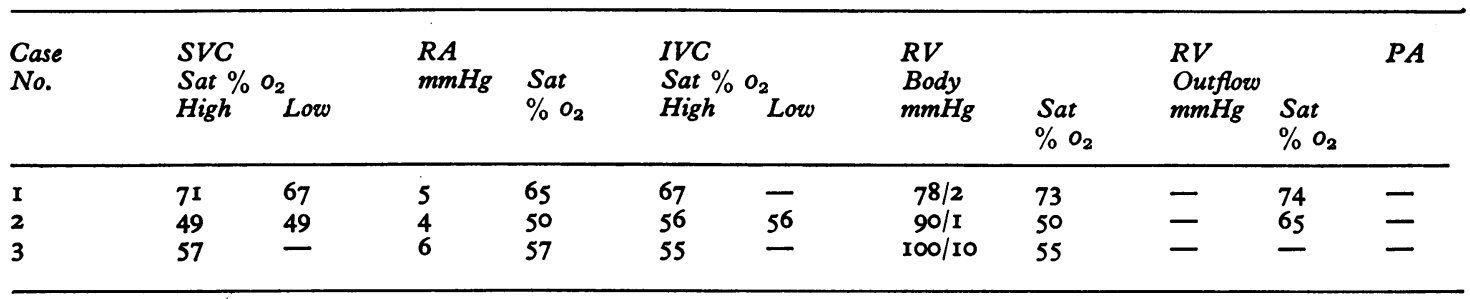

SVC - superior vena cava. Sat $\% \mathrm{o}_{2}$ - Percentage saturation of oxygen in blood. RA - right atrium. IVC - inferior vena cava. RV - right ventricle. PA - pulmonary artery. PV - pulmonary veins. LA - left atrium. LV - left ventricle.

Case I - Catheterization performed ro months before corrective surgery during which time her cyanosis increased.

Treatment At operation on 13 June (T.A.H.E.) through a median sternotomy, the right atrium was seen to be small. There were both left and right superior venae cavae. The right ventricle was much enlarged and the aorta and pulmonary artery arose from it. The pulmonary artery was small, being approximately onequarter the diameter of the aorta which was to its left. The right coronary artery arose from the aorta to pass immediately in front of the origin of the main pulmonary artery. It gave off two large branches to the body of the right ventricle and then continued normally. Cardiopulmonary bypass was instituted with cannulation of ascending aorta, right superior vena cava, and inferior vena cava. On occluding the left superior vena cava, no rise in left innominate pressure was recorded. It was therefore considered safe not to cannulate separately the left superior vena cava. On examination of the interior of the right ventricle, the diagnosis was confirmed. There was a

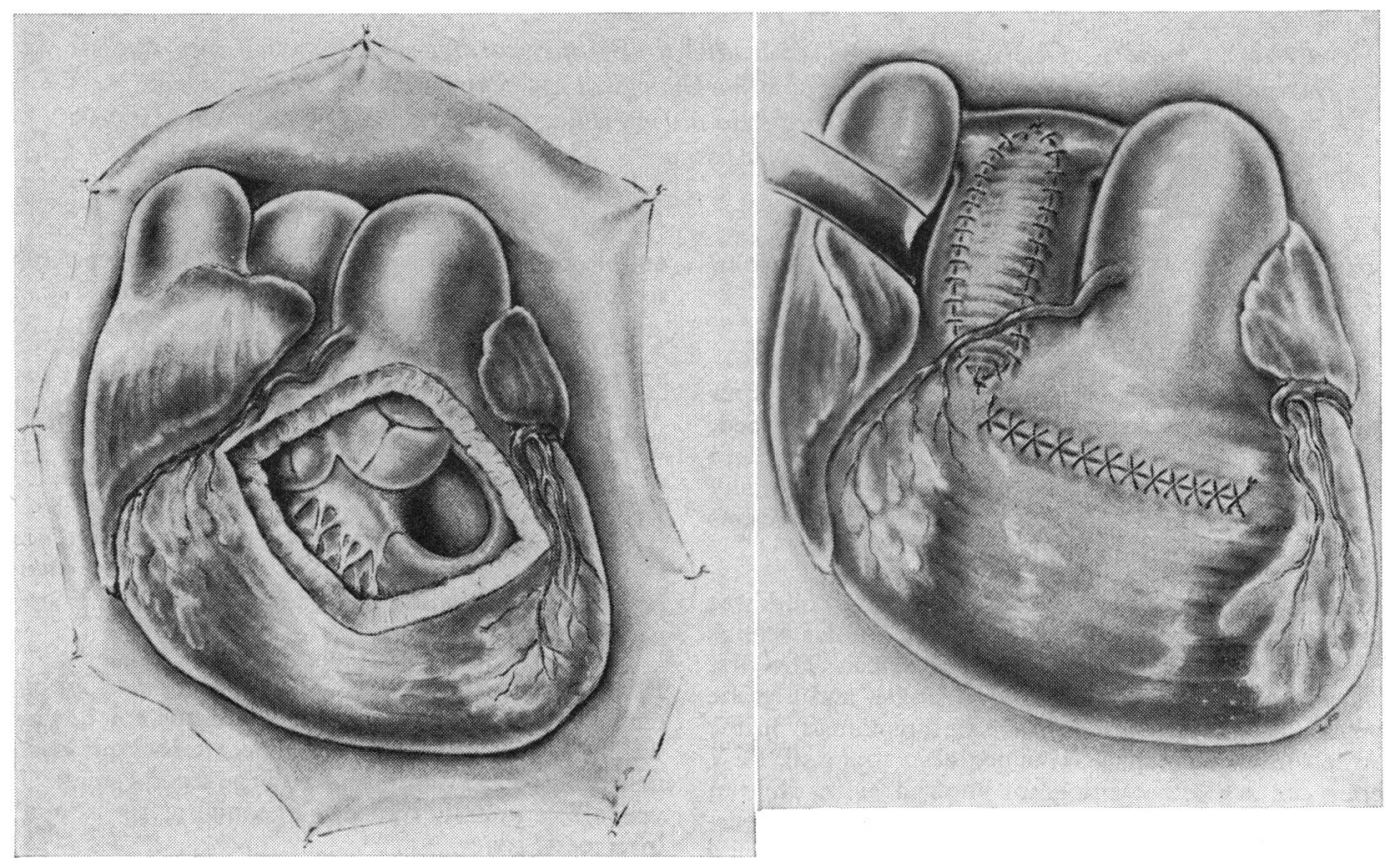

$A$

$C$

FIG. 3 Case I. A) The right ventricular anatomy as seen through the ventriculotomy. The pulmonary valve ring is one-third the size of the aortic valve ring. A subaortic ventricular septal defect can be seen, and the right coronary artery crossed anterior to the pulmonary valve ring. $B$ ) Attachment of the 'teflon' conduit to reroute the blood from the left ventricle to the aorta. Inset shows attachment of the conduit to the fused pulmonary and aortic valve rings. $C$ ) Right ventricular outflow tract patch placed posterior to the right coronary artery in order to relieve the pulmonary stenosis. (Reproduced from Journal of Thoracic and Cardiovascular Surgery.) 


\begin{tabular}{lllllll}
$\begin{array}{l}P V \\
\text { Sat } \\
\% O_{2}\end{array}$ & $\begin{array}{l}L A \\
m m H g\end{array}$ & $\begin{array}{l}\text { Sat } \\
\% o_{2}\end{array}$ & $\begin{array}{l}L V \\
m m H g\end{array}$ & $\begin{array}{l}\text { Sat } \\
\% o_{2}\end{array}$ & $\begin{array}{l}\text { Aorta } \\
m m H g\end{array}$ & $\begin{array}{l}\text { Sat } \\
\% o_{2}\end{array}$ \\
\hline- & 3 & 99 & $80 / 0$ & 99 & $78 / 50$ & 92 \\
$\overline{9}$ & 8 & 97 & $80 / 1$ & 99 & $90 / 56$ & 66 \\
99 & 6 & 85 & $90 / 0$ & 76 & $85 / 50$ & 62 \\
\hline
\end{tabular}

large ventricular septal defect of approximately the same diameter as the aorta, and both aorta and pulmonary artery could be seen to arise entirely from the right ventricle. The ventricular septal defect was predominantly subaortic in position. There was a substantial conus present underneath the aortic valve which was separated from the mitral and tricuspid valve rings by at least 1.5 $\mathrm{cm}$. Both subvalvar and valvar pulmonary stenosis were present. A small haemostat was passed into the pulmonary artery and opened, thereby rupturing the pulmonary valve cusps. An extensive infundibular resection was then performed, excising in all $9.5 \mathrm{~g}$ of muscle. This included a large parietal extension of the conus septum passing as the crista across the aortic conal myocardium. The pulmonary valve was then dilated up until a $1.2 \mathrm{~cm}$ bougie could be passed through into the main pulmonary artery. During a period of ischaemic arrest, a knitted 'dacron' patch, approximately $4 \mathrm{~cm} \times 2.5 \mathrm{~cm}$ was then attached to the inferior rim of the ventricular septal defect.

At this stage, it appeared that the ventricular septal defect might be inadequate to form the aortic outflow tract. A wedge was, therefore, excised from its anterosuperior margin. The remainder of the patch was then sewn into position. The left ventricular blood could then be ejected through the ventricular septal defect and into the aorta. A continuous $4 / 0$ suture was used for securing the patch in position, reinforced at intervals with 'teflon' backed interrupted sutures.

Diagnostic pressures taken within the left and right ventricles revealed peak systolic ratio of 0.8 . Six months after operation she is well and acyanotic.

\section{Case 4}

This patient died in 1958 at the age of 17 years. Cyanosis appeared at the age of 2 years becoming progressively more severe. At the age of 12 years, there was cyanosis, clubbing, a prominent parasternal impulse, and systolic thrill. A grade $5 / 6$ systolic murmur maximal at the second left intercostal space completed the positive clinical findings.

Electrocardiogram showed sinus rhythm, and right ventricular hypertrophy. Mean frontal plane $Q R S$ axis was $+150^{\circ}$ and a $\mathrm{qR}$ complex was present in V6. Chest $x$-ray showed situs solitus and a normal heart size (Fig. Id). She was subsequently lost to follow-up and died 5 years later.

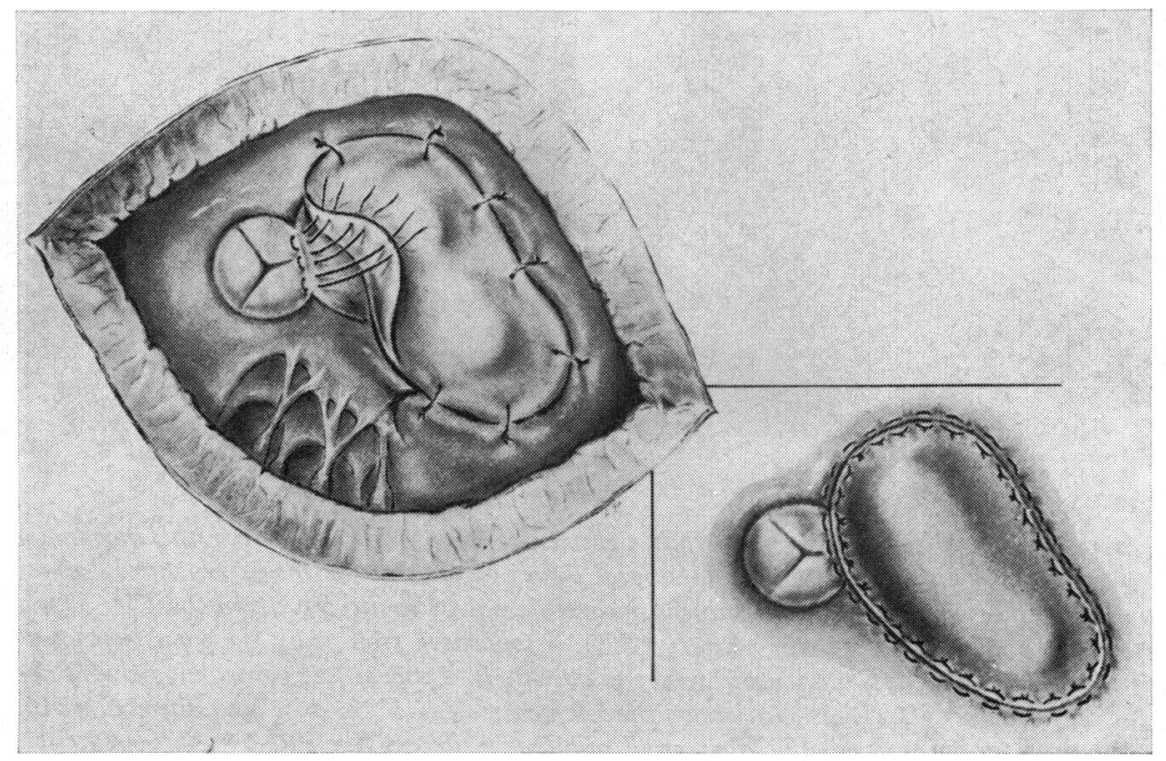



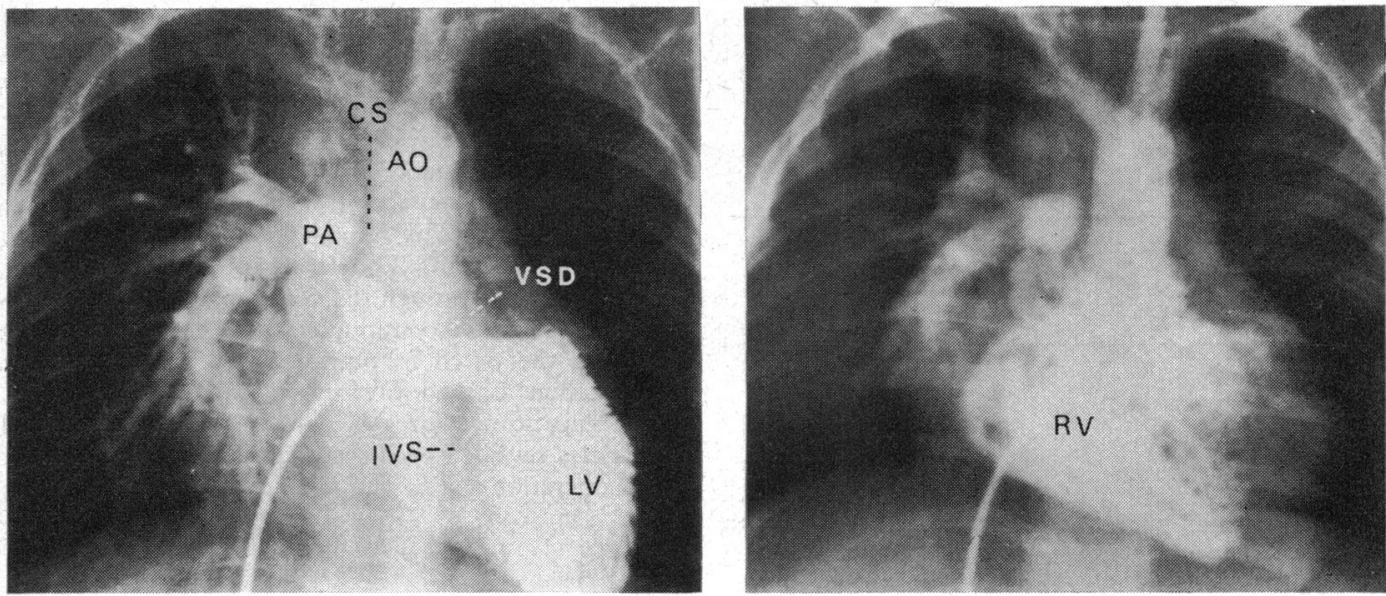

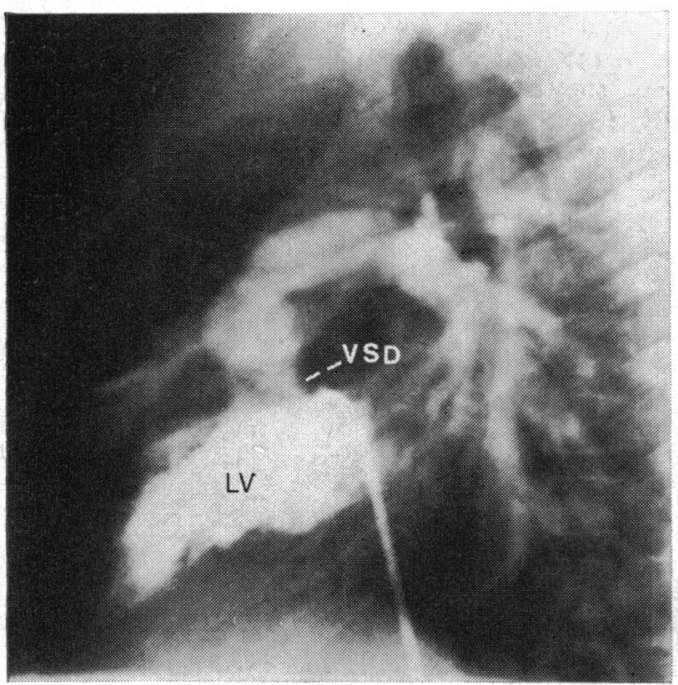

$B$

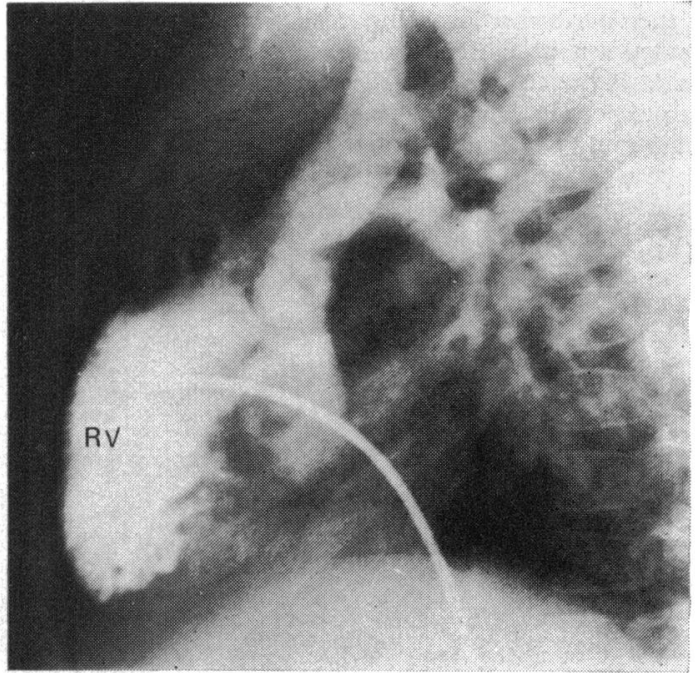

$D$

FIG. 4 Case 2. A) Anteroposterior left ventriculogram. Contrast leaves the morphological left ventricle ( $L V)$ through a ventricular septal defect (VSD) above the interventricular septum (IVS). Both great arteries fill simultaneously and do not arise directly from the $L V$. The aorta $(A O)$ is larger than the pulmonary artery $(P A)$, is separated from it by the conus septum $(C S)$, and is to the left. The left pulmonary artery is absent. $B$ ) Lateral left ventriculogram. The ventricular septal defect $(V S D)$ is seen above the left ventricle $(L V)$ and its boundaries separate the semilunar and mitral valves. The aorta and pulmonary artery are side by side and arise from the anterior right ventricle. C) Anteroposterior right ventricular angiogram. Both great vessels are seen to arise from a morphological right ventricle $(R V) . D)$ Lateral view. Right ventricular angiogram. This confirms the anterior position of the right ventricle $(R V)$. 
Necropsy findings The heart was in the left hemithorax and the viscera were arranged in situs solitus. The systemic veins drained to the right atrium, but the auricle was unusual in that it was juxtaposed to the left of the great arteries. The crista terminalis was poorly formed, the fossa ovalis widely patent, and its limbus formed a superior ridge between the juxtaposed auricles. The pulmonary veins drained to the left atrium.

The ventricles exhibited features of d-bulboventricular looping. The right atrioventricular orifice was guarded by a tricuspid valve, which possessed papillary muscles typical of the morphological right ventricle. The right surface of the ventricular septum was atypically smooth, showing no evidence of a trabecula septomarginalis. However, a conal papillary muscle arose directly from the septal surface. The left-sided atrioventricular valve was bicuspid and had papillary muscles of typical mitral valve pattern. The left-sided ventricle was finely trabeculated and its only exit was through a ventricular septal defect in the right anterior quadrant of the ventricle.

The outflow tracts of both great arteries were situated above the morphological right ventricle, and that of the aorta was to the left of the pulmonary artery. The two tracts were separated from each other by a thick muscular ridge, which arose from the central fibrous trigone between the atrioventricular valves. The ridge was orientated in the sagittal plane of the heart and was attached anteriorly to the parietal wall of the right ventricle. The pulmonary valve was bicuspid and arose from a muscular conus. Its left origin was the muscular ridge described above, which constituted the conus septum. Posteriorly the valve arose from the infolded ventricular aspect of the right anterior atrioventricular groove, and the muscular bar so formed separated the pulmonary valve from the tricuspid valve. The aortic valve was tricuspid and arose from a muscular conus at the same level as the pulmonary valve. Its origin was to the left of the conus septum, while posteriorly it arose from a similar muscular bar as that seen beneath the pulmonary valve. In this situation the bar represented the ventricular aspect of the infolded left atrioventricular groove. The two bars of muscle were continuous posteriorly, forming a $\mathrm{T}$ junction with the conus septum. Posterior to this junction the tricuspid and mitral valves were in continuity through the septal defect. The boundaries of the defect itself were formed superiorly by the left margin of the atrioventricular groove, anteriorly and inferiorly by the muscular septum, posteriorly by the junction of the atrioventricular groove, conus septum, and tricuspid-mitral valve continuity. The defect thus opened into the right ventricle beneath the aorta, being separated from the pulmonary artery by the conus septum.

The aorta was approximately twice as large as the pulmonary artery and arose anteriorly to its left. A single coronary artery took origin from the right anterior aortic sinus, and immediately bifurcated on the front of the heart. The left branch itself bifurcated, giving off an anterior descending artery and continuing into the left atrioventricular groove. The right branch coursed directly in front of the pulmonary artery to enter the right atrioventricular groove.
Histological findings The atrioventricular node was normally situated in the interatrial septum and was formed mainly by a fusiform tract which was directly continuous with the atrioventricular bundle. The atrial transitional cells impinging upon this tract were extremely attenuated and separated by unusually large amounts of connective tissue. The atrioventricular bundle passed through the central fibrous body on its right aspect, and was situated well posterior to the ventricular septal defect (Fig. 5A). The left bundle-branch immediately took origin from the main bundle as a broad sheet of cells, and this structure was also posterior to the defect. In this situation a membranous septum was present between the atrioventricular bundle and the central fibrous body (Fig. 5B). The bulk of the left bundle-branch had originated from the common bundle before the septal defect was observed, and the beginning of the posterior aspect of the defect was formed by the anterior free edge of the membranous septum. The right bundlebranch continued as a thin strip of cells astride the inferior rim of the defect (Fig. 5C) and descended subendocardially down the right side of the septum below the anterior edge of the defect. The right bundle-branch in this situation formed a broad sheet of cells reminiscent of the normal left bundle-branch (Fig. 5D), and at no stage did this structure run an intramyocardial course.

\section{Discussion}

All the patients presented with progressive cyanosis, clubbing, and effort intolerance. An ejection systolic murmur and single second sound were also constant findings. On the chest $x$-ray pulmonary vascular markings depended on the degree of pulmonary stenosis, being reduced in all. The cardiac silhouette helped to differentiate these cases from tetralogy of Fallot in that the straight upper left heart border suggested a left-sided ascending aorta.

These findings suggested a possible diagnosis of ventricular inversion with 1-TGA (corrected transposition). The electrocardiogram, however, was not typical of this condition as $Q$ waves were present over the left chest in 3 cases though in Case I the small $Q$ in $V_{4} R$ would have been consistent with this diagnosis.

The combination of the left-sided ascending aorta on the chest $x$-ray with a normal $Q$ wave pattern on the electrocardiogram suggests the possible diagnosis of d-bulboventricular loop with 1-malposition. Adding cyanosis to this combination allows the inference that the aorta is situated above the systemic venous ventricle, that there is a common ventricle situation, or that there is a ventricular septal defect with pulmonary outflow tract obstruction. Clearly precise diagnosis can only be reached after cardiac catheterization and angiocardiography. In all our studies identification of the 
460 Lincoln, Anderson, Shinebourne, English, and Wilkinson
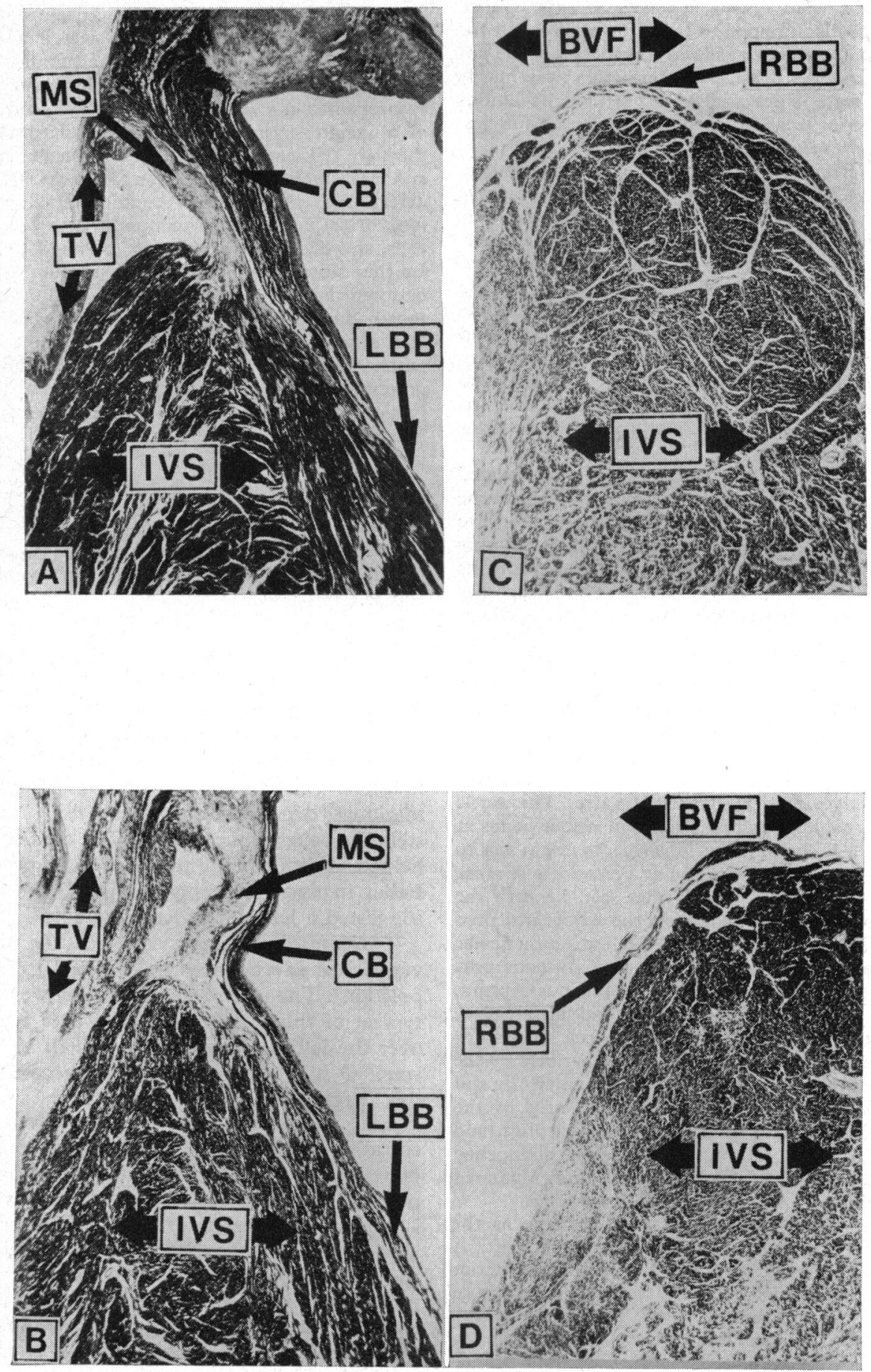
morphological left and right ventricles confirmed a d-bulboventricular loop in situs solitus (assessed from the chest $x$-ray). Left ventriculography demonstrated the only exit from the left ventricle to be a subaortic ventricular septal defect. This and right ventriculography revealed that both great arteries arose above the right ventricle and that semilunar atrioventricular valve discontinuity was present. Thus, in all cases an eventual diagnosis of double outlet right ventricle with 1-malposition and bilateral conus was made.

Although until 1972 only 3 cases had been described (Paul et al., 1968; Lincoln, 1972; Danielson et al., 1972), our experience and that of others (Blancquaert et al., 1973) indicates that this condition may be commoner than hitherto realized. Angiocardiographic differential diagnosis is from double outlet left ventricle or anatomically corrected malposition (situs solitus, d-bulboventricular loop, 1-malposition) with an anterior aorta arising from the morphological left ventricle (Van Praagh, 1973a).

\section{Surgical management}

This depends on the presence and severity of associated anomalies. Pulmonary stenosis, present in all of our cases, may limit pulmonary blood flow and require palliative shunting procedure before corrective surgery. In the absence of pulmonary stenosis, pulmonary hypertension with pulmonary vascular disease must develop, and here banding may be of help. Total correction at a later date is facilitated by the anatomical arrangement of the great vessels. The first successful correction was performed on Case I in May 197 I (Lincoln, 1972), and after this Danielson et al. (1972) repaired a similar case.

In total corrective surgery, the left ventricular outflow tract must be reconstructed and any pulmonary stenosis relieved. Reconstruction can be achieved by roofing in the ventricular septal defect with a full patch, at the same time incorporating the aortic valve ring. This necessitates suturing to the proximal free edge of the conus septum, which is usually a muscular structure as in Cases 3 and 4, and in the patient of Danielson et al. (1972), but may be fibrous as in Case $I$.

Relief of the pulmonary stenosis and fibromuscular obstruction of the right ventricular outflow tract can usually be achieved by resection of tissue inferior to the pulmonary valve ring. In 2 of the 3 cases successfully corrected, it was unnecessary to resort to an outflow tract patch. In Case I, however, resection of the subvalvar obstruction proved to be insufficient and an outflow tract patch was placed across the pulmonary valve.

In all cases so far reported, the right coronary artery passes anterior to the pulmonary outflow tract. It is most important to recognize this anomaly since insertion of an outflow tract patch becomes difficult as the coronary artery has to be dissected free of the surrounding tissues to allow placement of the patch. Alternatively, a method of treating the right ventricular outflow obstruction avoiding dissection of this coronary artery would be by means of a tube graft after the method of Rastelli, Titus, and McGoon (1967).

Pulmonary stenosis appears to be a relatively constant feature of this anomaly ( 7 of 8 reported cases including those presently reported) and is worthy of further consideration. In most of the cases, the obstruction has been subvalvar, composed of hypertrophied right ventricular trabeculae, but in our necropsied case a bicuspid pulmonary valve produced the stenosis. In the case reported by Blancquaert et al. (1973) fibrotic leaflets were present in the subpulmonary area and these structures may well have corresponded to the fibrous material removed in our Case I. The associated juxtaposed atrial appendages are of note since Case 4 and the case of Danielson et al. (1972) both

FIG. 5 Sample photomicrographs of the specialized tissue from Case 4 studied histopathologically. All sections are cut in the frontal plane and are presented as viewed from the front. $A$ ) Section showing the perforating atrioventricular bundle (CB). Having pierced the fibrous ring, the bundle is descending in the substance of a membranous septum-like structure (MS) and has already begun to give off the left bundle-branches (LBB). IVS-interventricular septum. $T V$ - tricuspid valve. B) Section anterior to Fig. A, showing the origin of the left bundle-branch $(L B B)$ from the common bundle $(C B)$. The common bundle is still related to the membranous septum-like structure (MS). C) Section anterior to Fig. $B$ through the region of the ventricular septal defect which represents the bulboventricular foramen $(B V F)$. The right bundle-branch $(R B B)$ is a direct continuation of the common bundle and is situated on top.of the septum (IVS). The left bundle-branch is not related to the defect in this situation. D) Section through the anterior part of the defect. The right bundle-branch is descending the septal surface in a subendocardial position $(R B B)$. This relation is reminiscent of the normal left bundle-branch, and quite unlike the normal right bundle-branch. 
exhibited this anomaly. The malformation reflects maldevelopment at an early stage of cardiac growth (Anderson and Ashley, 1974).

\section{Conducting tissue}

The arrangement of the conducting tissue in the case studied here is unusual in that only the right bundle-branch is related to the ventricular septal defect. The common bundle and left bundlebranch are posterior beneath a well-formed 'membranous' septum which, however, does not close the defect. This arrangement means that surgically the conducting tissue is relatively safe since only the right bundle-branch occupies the area of the defect 'at risk'. It is similar to the arrangement in Fallot's tetralogy where the left bundle courses below the rim of the defect, and only the very posterior margin on the defect is related to the perforating bundle (Lev, 1959). In contrast, in simple 'membranous' septal defects, the bifurcation and both branches are usually draped across the ventricular septal crest (Truex and Bishof, 1958). However, despite the relatively safe position of the left bundle in Fallot's tetralogy, recent experience has demonstrated that right bundle-branch block with left axis deviation is a common postoperative electrocardiographic finding, and that this electrocardiographic feature is directly referable to fascicular damage (Godman, Roberts, and Izukawa, 1974). Since the left bundle is unlikely to be directly traumatized in these cases, the possibility is raised that trauma to the right bundle-branch may track proximally to involve the bifurcation (Latham and Anderson, 1972). If at all possible, therefore, it would be advantageous to avoid trauma to the right bundle.

\section{Morphogenesis}

The cases presently described bear close resemblance to the type of double outlet right ventricle with subpulmonary defect classified as TaussigBing syndrome (Van Praagh, 1968). Both conditions exhibit a bilateral conus with the ventricular septal defect beneath the left-sided great artery, and from the aspect of conal morphology, the two malformations are very similar. However, in the TaussigBing situation the left-sided conus gives rise to the pulmonary artery, whereas in double outlet right ventricle with 1 -malposition the aorta arises from this conus. The Taussig-Bing heart can be considered to be derived by cardiac development involving lack of normal conal inversion (Goor, Dische, and Lillehei, 1972) and lack of normal conal absorption (Goor et al., 1972; Anderson et al., 1974). However, it is more difficult to explain the embryogenesis of double outlet right ventricle with 1-malposition. Goor and Edwards (1973) suggested that complete isolated conal inversion in reverse would produce the latter anomaly from the starting point of the Taussig-Bing anomaly. This explanation is not entirely satisfactory since it is postulated that the normal conal inversion, which takes the aorta to the left ventricle, is communicated to the truncus, producing normal spiralling of the great arteries (Los, 1968; Goor et al., 1972). It may, therefore, be expected that reverse conal inversion, as postulated for double outlet right ventricle with 1-malposition (Goor and Edwards, 1973), would also produce spiralling great arteries. As presently demonstrated, the great arteries do not spiral in this condition.

An alternative explanation is that the aortopulmonary septum, which separates the 4th and 6th aortic arches at their proximal ends (Los, 1968), could fuse with the conotruncal septum in reverse. This would connect the 4th (aortic) arch to the left rather than right-sided conus, and would produce double outlet right ventricle with 1-malposition and parallel great arteries. It can be argued that such an hypothesis is closely akin to the 'straight septum hypothesis' (Van Mierop and Wiglesworth, 1963) which has been claimed to be untenable for the production of transposed great arteries (Los, 1968; Goor et al., 1972; Van Praagh, 1973b; Anderson et al., 1974). As presently postulated, it is important to realize that the 'plugging-in' of the arteries is secondary to conal maldevelopment, which should still be considered as the primary anomaly. We have no direct evidence to support this concept vis-á-vis 'reversed conal inversion' other than the difficulty of explaining parallel arteries by the latter hypothesis. However, since double outlet right ventricle with d-malposition is part of a spectrum from the normal heart to classically complete transposition (Lev et al., 1972; Goor and Edwards, I973), it might be expected that double outlet right-ventricle with 1-malposition would be part of a similar spectrum. Anatomically corrected malposition (Van Praagh and Van Praagh, 1967; Goor and Edwards, 1973) can be considered as part of this spectrum. Study of other hearts which may be assigned to this spectrum could well elucidate the exact morphogenesis of double outlet right ventricle with 1-malposition.

\section{References}

Anderson, R. H., and Ashley, G. T. (1974). Anatomical development of the cardiovascular system. In Scientific Foundations of Paediatrics, p. 188. Ed. by J. A. Davis and J. Dobbing. Heinemann, London.

Anderson, R. H., Wilkinson, J. L., Arnold, R., and Lubkiewicz, K. (1974). The morphogenesis of bulboventricular malformations. I. Consideration of embryogenesis in the normal heart. British Heart fournal, 36, 242. 
Blancquaert, A., Defloor, E., Bossaert, L., Kunnen, M., de Maegd, M., and Derom, F. (1973). Double outlet right ventricle with 1-malposition of the great arteries, ventricular d-loop and three fibrotic leaflets in a stenotic subpulmonary conus. British Heart fournal, 35, 770.

Danielson, G. K., Ritter, D. G., Coleman, H. N., and DuShane, J. W. (1972). Successful repair of doubleoutlet right ventricle with transposition of the great arteries (aorta anterior and to the left), pulmonary stenosis, and subaortic ventricular septal defect. Fournal of Thoracic and Cardiovascular Surgery, 63, 741.

Godman, M. J., Roberts, N. K., and Izukawa, T. (1974). Late postoperative conduction disturbances after repair of ventricular septal defect and tetralogy of Fallot analysis of His bundle recordings. Circulation, 49, 214.

Goor, D. A., Dische, R. and Lillehei, C. W. (1972). The conotruncus: $\mathrm{I}$. Its normal inversion and conus absorption. Circulation, 46, 375.

Goor, D. A., and Edwards, J. E. (1973). The spectrum of transposition of the great arteries: with specific reference to developmental anatomy of the conus. Circulation, 48 , 406.

Latham, R. A., and Anderson, R. H. (1972). Anatomical variations in atrioventricular conduction system with reference to ventricular septal defects. British Heart fournal, 34, 185.

Lev, M. (1959). The architecture of the conduction system in congenital heart disease. Tetralogy of Fallot. Archives of Pathology, 67, 572.

Lev, M., Bharati, S., Meng, C. C. L., Liberthson, R. R., Paul, M. H., and Idriss, F. (1972). A concept of doubleoutlet right ventricle. Fournal of Thoracic and Cardiovascular Surgery, 64, 271.

Lincoln, C. (1972). Total correction of d-loop double-outlet right ventricle with bilateral conus, 1-transposition, and pulmonary stenosis. Fournal of Thoracic and Cardiovascular Surgery, 64, 435.

Los, J. (1968). Embryology. In Paediatric Cardiology, p. I. Ed. by $\mathrm{H}$. Watson. Lloyd-Luke, London.

Paul, M. H., Van Praagh, S., and Van Praagh, R. (1968). Transposition of the great arteries. In Paediatric Cardiology, p. 576. Ed. by H. Watson. Lloyd-Luke, London.

Rastelli, G. C., Titus, J. L., and McGoon, D. C. (1967). Homograft of ascending aorta and aortic valve as a right ventricular outflow. An experimental approach to the repair of truncus arteriosus. Archives of Surgery, 95, 698.

Truex, R. C., and Bishof, J. K. (1958). Conduction system in human hearts with interventricular septal defects. Fournal of Thoracic Surgery, 35, 421.

Van Mierop, L. H. S., and Wiglesworth, F. W. (1963). Pathogenesis of transposition complexes. III. True transposition of the great vessels. American fournal of Cardiology, 12, 233.

Van Praagh, R. (1968). What is Taussig-Bing malformation? Circulation, 38, 445 .

Van Praagh, R. (1973a). Conotruncal malformations. In Heart Disease in Infancy, p. I4I. Ed. by B. G. BarrattBoyes, J. M. Neutze, and E. A. Harris. Churchill-Livingstone, London.

Van Praagh, R. (1973b). Do side-by-side great arteries merit a special name? American fournal of Cardiology, 32, 874.

Van Praagh, R., and Van Praagh, S. (1967). Anatomically corrected transposition of the great arteries. British Heart fournal, 29, 112 .

Requests for reprints to Christopher Lincoln, Esq., F.R.C.S., Brompton Hospital, Fulham Road, London $\mathrm{SW}_{3}$ 6HP. 